\title{
PROPOSAL FOR A PROGRAM TO ENHANCE RENAL TRANSPLANTATION OPPORTUNITY FOR HIGHLY SENSITIZED PATIENTS
}

\author{
Proposta de um programa para aumentar a oportunidade de transplante renal para pacientes \\ hipersensibilizados
}

\author{
Érika Fernandes Campos ${ }^{1,4}$, Ilias loannis Nikolaos Doxiadis ${ }^{3}$, Julia Temin ${ }^{4}$, Andrea Plothow ${ }^{4}$, Elaine Cristina Bellintani ${ }^{4}$, Yuriko \\ Miyamoto4, Lidia Vieira Dantas, José Osmar Medina-Pestana², Frans Claas ${ }^{3}$, Maria Gerbase-DeLima ${ }^{1,4}$
}

\begin{abstract}
Purpose: The accumulation of highly sensitized patients (HSP) on renal transplant waiting lists is a universal problem and finding donors for them represents a major challenge for organ distribution organizations. The purpose of this report is to describe a possible Brazilian version of the Eurotransplant Acceptable Mismatch program and the results of a study performed to test its efficiency. Method: The acceptable mismatches were defined with the single antigen beads Luminex assay, each test being individually interpreted with aid of the HLAMatchmaker algorithm. Negative-crossmatch prediction was validated in $86 \mathrm{~T}$ cell crossmatches using complement dependent cytotoxicity with anti-human globulin. Results: The estimation of the chances of 40 HSP to find a donor through the program showed that about $70 \%$ of them would be offered an ABO compatible, zero HLA-DR mismatched, T and B cell crossmatch negative graft within a two-year period after joining the program. On the other hand, for about $30 \%$ of the patients, the chances to find a suitable donor would be minimal, even after three or five years. Conclusions: We estimated that around $70 \%$ of the HSP would clearly benefit from the algorithm proposed in this study. On the other hand, those patients for whom it would be highly improbable to find a compatible donor would be primary candidates for desensitization/antibody reduction protocols. Therefore, we concluded that the information regarding the transplantability of each HSP provided by the algorithm herein described is a powerful tool for a proper management of highly sensitized patients in regional, national and international organizations as to deceased donor kidneys distribution.
\end{abstract}

Keywords: Antibodies, HLA, Kidney Transplantation, Histocompatibility.

\footnotetext{
Instituições:

1 Immunogenetics Division, Pediatrics Department, Universidade Federal de São Paulo, São Paulo, SP, Brasil,

2 Nephrology Division/Hospital do Rim e Hipertensão, Universidade Federal de São Paulo, São Paulo, SP, Brasil,

3 EurotransplantReference Laboratory, Department of Immunohaematology and Blood Transfusion, Leiden University Medical Center, Leiden, The Netherlands,

4 AFIP (Associação Fundo de Incentivo à Psicofarmacologia), São Paulo, SP, Brasil.
}

\section{Correspondência:}

Érika Fernandes Campos

Rua Loefgreen, 1235 - CEP 04040-031 - São Paulo, SP, Brazil

Tel: 55-11-21017100;

Fax: 55-11-55727669

E-mail: erika@igen.epm.br

This work was supported by a grant from the Associação Fundo de Incentivo à Psicofarmacologia (AFIP), São Paulo, SP, Brasil.

Recebido em: 30.03.2010

Aceito em: 09.04.2010

\section{INTRODUCTION}

Highly sensitized patients (HSP) tend to accumulate on waiting lists for renal transplantation because they have a low probability of finding a negative crossmatch organ via standard allocation procedures. Performing crossmatches with every available ABO compatible blood group deceased donor has been implemented in some organ allocation programs, ${ }^{1,2}$ but this proved to be a method of limited efficiency and a time-consuming procedure, often leading to an increase in cold ischemia time. Presently, two different strategies are being most frequently considered: (1) finding a suitable donor based on HLA mismatches against which a negative crossmatch is expected, being used by Eurotransplant, and called the Acceptable Mismatch (AM) Program;3-6 (2) removal of the alloantibodies through desensitization/antibody reduction protocols.,8

Brazil, a country with more than 198 million ethnically diverse inhabitants, distributed in an 8.2 million square kilometer area has a successful transplantation program which is regulated, controlled and fully financed by the Public Health System. In 2009, 4259 kidney transplants were performed in Brazil, 60\% of which with kidneys from deceased donors. More than $40 \%$ of the deceased donors kidney transplants were performed in the State of São Paulo (Registro Brasileiro de Transplantes, Ano XV, 4, 2009) where the deceased donors kidney allocation system is based on HLA-A, B and DR compatibility, in two tiers. In the first tier, all recipients on the waiting list (approximately 10,000 individuals) are considered for an ABO compatible and zero HLA-A, B, DR mismatched donor. The second tier considers patients from one of 
the two regional waiting lists and the kidney distribution criteria are ABO identity and HLA compatibility (maximum points of 1 , 4 and 6 , corresponding to zero HLA-A, B and DR mismatches (MM), respectively). Kidneys from donors up to 18 years of age go to recipients up to 18 years old. The only prioritization criterion is the lack of vascular access to dialysis. Equally eligible patients at any point in the priority order are differentiated by means of a point score that considers the waiting time level of HLA sensitization recipient age, and diabetes (http://www.saude.sp.gov.br/resources/ cidadao/servicos/transplantes/e_rs-94_300605.pdf). Pre-transplant crossmatches include T cell crossmatch by complement dependent cytotoxicity with anti-human globulin (CDC-AHG), and B cell crossmatch by CDC. Flow cytometry crossmatch is not mandatory. In order to enhance the chances of HSP finding a suitable donor, we propose the utilization in Brazil, of a program similar to the AM Program being use in Eurotransplant, in which the highest priority is given to HSP as soon as a compatible donor with the patient's antibody profile becomes available. ${ }^{3-6}$ Here, we describe an algorithm intended to be initially used in the State of São Paulo, and afterwards to be adapted for implementation in other states or regions in Brazil.

To assess the effectiveness of the proposed AM program to enhance the kidney transplantability of HSP, we calculated the chances of 40 randomly selected, ethnically diverse HSP from the São Paulo waiting list of finding a suitable donor, considering $\mathrm{ABO}$ and HLA-A, B, DR phenotypes of 1,705 actual kidney graft donors from the State of São Paulo, and the availability of 483 kidney donors per year, which corresponds to the actual amount of deceased donors in the State of São Paulo observed along one year period from September 1, 2008 to August 31, 2009.

\section{METHOD}

\section{Patients}

The study included randomly selected ethnically diverse 40 patients waiting for a kidney from deceased donors with class I panel reactive antibodies (PRAs) $\geq 80 \%$, as defined by multiplex bead Luminex assay (LabScreen $®$ PRA, One Lambda Inc, Canoga Park, USA) (Table 1). All patients were genotyped in our laboratory for HLA class I and II antigens by PCR-SSP or PCR-SSO, at a low to medium resolution level. Patients were considered homozygous for HLA-A, -B or -DR when the second antigen was not detected. This study was approved by the Institutional Medical Ethics Committee and all patients signed the informed consent.

Table 1: Patient characteristics

\begin{tabular}{lc}
\hline Variables & $\begin{array}{c}\text { Highly Sensitized Patients } \\
(\mathbf{n = 4 0 )}\end{array}$ \\
\hline Age* $^{*}$ & $43.5 \pm 13.3$ \\
Gender, females & $62.5 \%$ \\
Race, Caucasians & $71.8 \%$ \\
PRA class I (\%)* & $92.4 \% \pm 5.9 \%$ \\
PRA class I $\geq 95 \%$ & $52.5 \%$ \\
PRA class II (\%)* & $41.6 \% \pm 36.4 \%$ \\
Known sensitizing events & \\
$\geq 1$ pregnancy & $80 \%$ of the females \\
$\geq 1$ blood transfusion & $91.4 \%$ \\
$\geq 1$ prior transplant & $50 \%$ \\
\hline
\end{tabular}

* Data are given as average $\pm S D$

\section{Determination of HLA-A, B acceptable mismatches (AMs)}

By definition, AMs are HLA antigens against which no preformed antibodies are detected. ${ }^{3}$ Algorithm used to assess HLA class I AMs in the present study combines information derived from the HLAMatchmaker analysis with the results of the serum screening with single antigen beads Luminex assay.

HLAMatchmaker predicts antibody formation against HLA antigens, taking into account conformational epitopes, named "eplets", ${ }^{9}$ which are present in the HLA molecules of the patient. After inserting the HLA-A, B alleles of the patient into the program, it shows which allogeneic HLA-A, B alleles do not have eplet incompatibilites with the patient's HLA. It is assumed that it is not possible to form antibodies against a HLA allele with $0 \mathrm{MM}$ at the eplet level. We used the ABC Eplet Antibody Analysis Version 1.3, freely available for download at http://www.hlamatchmaker.net/. As this version requires the entry of HLA alleles while the HLA typing of our patients was at low/ intermediate level, we used the most frequent allele of the corresponding specificity, respecting the ethnic group, according to HLA frequencies from Brazilian populations, available for public search at http://www.allelefrequencies.net.

The HLA-A, B AMs were defined by Luminex-single antigen (SA) beads assay (LabScreen ${ }^{\circledR}$ Single Antigen; One lambda Inc) and the eplet version of HLAMatchmaker. The cutoff of the SA assay was individually determined for each serum, accordingly to the following steps: (a) firstly, we considered reactions with nMFI (normalized median fluorescence intensity) $<500$ as truly negative 10 and we checked whether the beads carrying the patient's own HLA antigens and antigens with $0 \mathrm{MM}$ at the eplet level presented MFIs <500; (b) aiming to define a higher cutoff that could be used to discriminate acceptable from unacceptable MM, we selected the first pair of reactions corresponding to two different alleles of the same specificity that presented nMFI $\geq 500$ and the cutoff was set immediately below the allele with the lowest nMFI; (c) for the other specificities represented by more than one allele, we considered as AMs only specificities with both alleles below the individualized cutoff; in order to validate this cutoff, the alleles present in beads with nMFI values below 500 were recorded as negative reactions in the HLAMatchmaker, and the alleles with the corresponding eplets were interpreted as additional AMs; (d) the additional AMs were then analyzed in terms of their nMFI value in the single antigen assay, and the individualized cutoff was accepted if only up to five beads carrying one of those additional alleles/specificities presented nMFI values above the cutoff. This number was chosen considering results regarding HLAMatchmaker prediction of negative reactions in the SA assay. ${ }^{11}$ Otherwise, the individualized cutoff was not accepted and the original cutoff at $500 \mathrm{nMFI}$ was considered. After establishing the AMs, we generated a list of phenotypes of potential donors for each patient against whom a negative crossmatch was expected, by combination of the patients' own HLA antigens with the acceptable mismatches (list of acceptable phenotypes).

In order to validate the prediction of a negative $\mathrm{T}$ cell crossmatch, we performed CDC-AHG crossmatches against $\mathrm{T}$ cells bearing phenotypes present in the list of acceptable phenotypes. 


\section{Calculation of the probability of finding a donor}

The probability of finding a negative $\mathrm{T}$ cell crossmatch, HLA-DR and ABO compatible donor were calculated using the software developed by the Eurotransplant Reference Laboratory, Leiden University Medical Center. ${ }^{6}$ For the Brazilian version of the AM program, we used a 1,705 kidney donors database from the State of São Paulo containing information on ABO blood group and HLA-A,B,DR phenotypes, and we considered the availability of 483 donors per year corresponding to the actual amount of effective deceased kidney donors in the State of São Paulo in the 12 month period that preceded our analysis. Previous analysis in Eurotransplant had shown that the use of donor HLA phenotypes gives a better prediction of the chance to find a negative crossmatch donor than considering the HLA antigen frequencies among the donor population.

\section{RESULTS}

\section{HLA-A, B AMs determination}

Using only the HLAMatchmaker algorithm, we were able to set 1 to 5 AMs (total of 59) for $27 / 40$ patients. In almost every case (94.9\%) beads corresponding to these 59 AMs showed reactions in the single antigen assay with lower than 1,500 nMFI (normalized median fluorescence intensity), with $88.1 \%$ of beads presenting lower than 500 nMFI reactions.

The initially established cutoffs for single antigen assay were validated by the Matchmaker in 33/40 (82.5\%) of the cases. The mean $( \pm$ SD) nMFI of these cutoffs was $1,509( \pm 927)$, and in 31 out of those 33 cases, the individualized cutoff was higher than 500 nMFI. In cases in which the initially set cutoff was not validated, we considered as AMs the alleles corresponding to beads that presented lower than 500 nMFI.

The combination of defined AMs, and patients' own HLA-A, B phenotypes generated from 25 to 64,638 acceptable phenotypes for each patient.

\section{Validation of the prediction of negative CDC-AHG T cell crossmatch}

In order to validate the prediction of negative $\mathrm{T}$ cell crossmatches, we performed 86 T-CDC-AHG crossmatches using sera from 18 patients and target cells with AMs, and all of them were negative.

\section{Simulation of the application of the algorithm for increasing the chances of transplantation}

We calculated the probability of $40 \mathrm{HSPs}$ finding an ABOcompatible, fully HLA-DR compatible donor with an acceptable HLA-A, B phenotype, considering the ABO-HLA donor database in the State of São Paulo and the availability of 483 donors per year. Figure 1 show probabilities of finding a donor in one, two, and three years after entering the program.

For the 21 HSPs subgroup with class I PRA $\geq 95 \%$, we compared their chances of finding an ABO-compatible, zero HLA-A, B, DR mismatched donor, with the chance of finding a suitable donor through the AM program. As shown in Figure 2, the AM program would provide a clear benefit for 13 of such patients $(62 \%)$. On the other hand, 8/21 patients would not find a suitable donor even in a five-year period after entering the program.
Figure 1: Estimated numbers of donors offered to each patient within one, two, and three-year periods after entering the AM program. Each group of three aligned columns represents one patient.

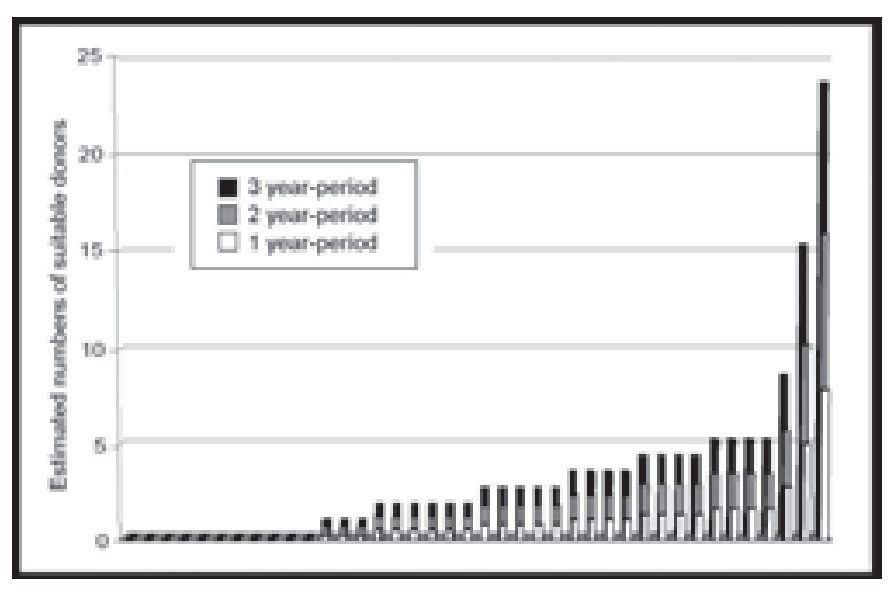

Figure 2: Estimated numbers of donors offered to patients with PRA $\geq 95 \%$ within a 5-year period after entering the program: comparison between the regular allocation system (gray column) and the AM algorithm (black column).

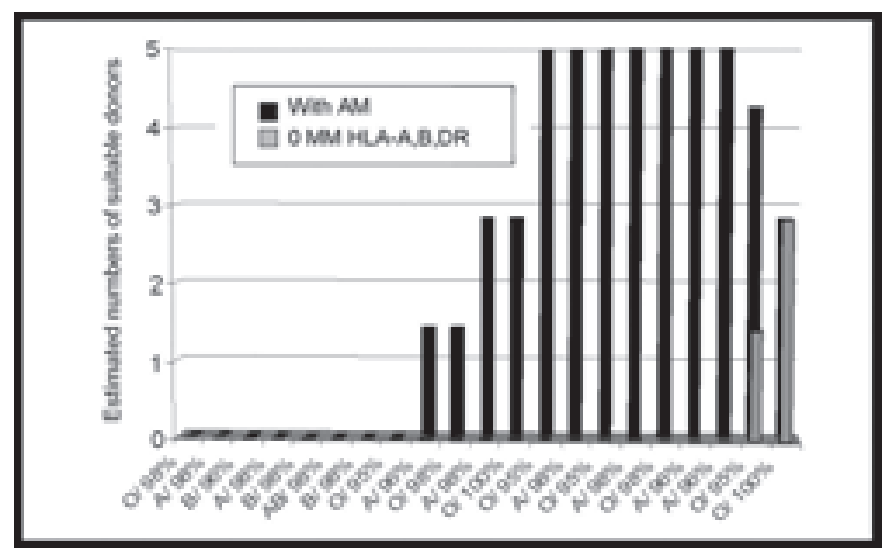

\section{DISCUSSION}

The purpose of the proposed algorithm is to select patients that should be mandatorily crossmatched against a given donor against who the crossmatch is predicted to be negative. The decision to perform the transplant according to the crossmatch results will depend on the transplantation center policy. Therefore, the proposed algorithm increases the transplantability without interfering in the transplant outcomes, since it does not interfere in the current transplantation practices of the donor selection by the transplantation team.

Since the mainstay of the AM program is the correct assignment of the absence of clinically relevant antibodies in the HSP sera, our first concern was to use the single antigen beads Luminex assay to correctly define the absence of missing antibodies against specific HLA antigens. By utilizing results of the single antigen bead assay conjugated to information of HLA eplets compatibility attained from the HLAMatchmaker algorithm, as suggested by Duquesnoy, ${ }^{12}$ we were able to individualize the cutoff for negativity in the single 
antigen assay for 33 out of the 40 sera tested (82.5\%). As in the majority of cases the cutoff could be placed at a higher than 500 nMFI level, it was possible to include more specificities such as AMs than it would be possible strictly using the 500 nMFI cutoff.

This individualized cutoff enabled us to predict a negative T-CDCAHG crossmatch in $100 \%$ of 86 crossmatches performed with sera from 18 HSP against T-cells with acceptable phenotypes. For allocation programs considering flow cytometry crossmatch positivity, a contra-indication for transplantation, it would be mandatory to test whether the cutoffs considered in the present study would also predict a negative flow cytometry crossmatch. We believe that this would be true, considering observations published by other authors. ${ }^{13-16}$

Our estimation of HSP chances for HLA class I antibodies to find a suitable renal graft from a deceased donor was that 37.5\%, 65\% and $72.5 \%$ of them would find a donor within one, two, and three years after inclusion in the program, respectively. It should be noticed that such figures are derived from estimations based on the anti-HLA-A and -B evaluation, but not anti-HLA-C antibodies. Anti-HLA C antibodies could not be taken into account in our study because in our kidney allocation algorithm the donors were not HLA-C typed. In a recent survey from our laboratory (unpublished data) on 113 patients with class I PRA $>80 \%$, 53.1\% had anti-HLA-C antibodies along with anti-HLA-A and/ or HLA-B antibodies, and none had only anti-HLA-C antibodies. Similar data were reported in another study.$^{17}$ Therefore, although sensitization to HLA-C is considerable less common than to HLA-A or B, we should expect some positive crossmatches due to these antibodies that it would lower the current estimation of finding a crossmatch negative donor.

The fact that some patients present anti-HLA-DQ antibodies and donors are not routinely typed for HLA-DQ poses another problem to predict negative B cell crossmatches. An analysis performed in our laboratory on anti-HLA-DQ and anti-HLA-DP antibodies in patients on the waiting list for kidney transplant with class II PRA $\geq 80 \%$ (based on DRB1 specificities) showed that $84.8 \%$ had also anti-HLA DQ antibodies, while $8.1 \%$ had only anti-HLA-DQ, and $1 \%$ had only anti-HLA-DP antibodies (unpublished data). In order to minimize chances of positive $\mathrm{B}$ cell crossmatches due to anti-DQ antibodies, we only considered possible donors those with zero HLA-DR mismatches, since these donors would often present zero HLA-DQ mismatches, considering the existing high linkage unbalance between HLA-DR and DQ genes. Although being not the ideal approach, it was the best alternative to deal with the lack of HLA-DQ typing knowledge of donors. It should be noticed that this approach limits the donor pool and as a consequence leading to an underestimation of transplantability. Therefore, the inclusion of HLA-DQ typing of deceased donors in the algorithm to the recipient selection would be highly recommended, and, ideally, donors should be also typed for HLA-C and DP specificities.

\section{CONCLUSION}

We estimated that around $70 \%$ of HSP would clearly benefit from the Acceptable Mismatch program proposed in this study. On the other hand, those patients for whom it would be highly improbable to find a donor would be primary candidates for desensitization/ antibody reduction protocols. Results of this study should encourage the discussion concerning the application of this program not only in Brazil, but also in other countries that do not have yet an effective program to enhance the transplantability of highly sensitized patients.

\section{ACKNOWLEDGEMENTS}

The authors acknowledge the State of São Paulo Health Secretariat for providing the donor ABO and HLA phenotypes database.

\section{RESUMO}

Objetivo: O acúmulo de pacientes hipersensibilizados nas listas de espera de transplante renal é um problema universal e achar doadores para os mesmos representa um grande desafio para organizações de distribuição de órgãos. O objetivo deste trabalho é descrever uma possível versão brasileira do programa "Eurotransplant Acceptable Mismatch" e relatar os resultados de um estudo realizado para testar sua eficiência. Método: As incompatibilidades aceitáveis foram definidas pelo teste Luminex com esferas recobertas por um único antígeno, sendo cada teste interpretado individualmente, com o auxílio do algoritmo “HLAMatchmaker”. A predição de prova cruzada negativa foi validada em 86 provas cruzadas negativas T, utilizando o método de citotoxicidade dependente de complemento sensibilizado com antiglobulina humana. Resultados: A estimativa das chances de 40 pacientes hipersensibilizados encontrarem um doador através do programa mostrou que para aproximadamente $70 \%$ dos mesmos haveria oferta de rim com compatibilidade no sistema ABO, sem incompatibilidades HLA-DR e provas cruzadas T e B negativas, dentro de um período de dois anos após a entrada no programa. Por outro lado, para cerca de 30\% dos pacientes, as chances de encontrar um doador seriam mínimas, mesmo dentro de períodos de três a cinco anos. Conclusões. Nós estimamos que em torno de $70 \%$ dos pacientes hipersensibilizados claramente beneficiar-se-iam do algoritmo proposto neste estudo. Por outro lado, os pacientes para os quais o achado de um doador fosse altamente improvável seriam candidatos a protocolos de dessensibização/ redução de anticorpos. Concluímos que a informação a respeito da transplantabilidade de cada paciente fornecida pelo algoritmo aqui descrito é uma ferramenta poderosa para um adequado manejo de pacientes altamente sensibilizados em programas regionais nacionais e internacionais de distribuição de órgãos de doadores falecidos.

Descritores: Anticorpos, HLA, Transplante renal, Histocompatibilidade. 


\section{REFERÊNCIAS}

1. Tardif GN, McCalmon RT Jr. SEOPF high-grade match algorithm: the effect of HLA matching with ROP trays in transplanting highly sensitized patients. Southern Organ Procurement Foundation. Clin Transplant. 1996;10:594.

2. MacQueen JM, Sanfilippo FP, Thacker L, Ward FE. Regional organ procurement (ROP) trays in renal allograft distribution and outcome. Clin Transplant. 1997;11:488.

3. Claas FH, de Waal LP, Beelen J, Reekers P, Berg-Loonen PV, de Gast E et al. Transplantation of highly sensitized patients on the basis of acceptable HLA-A and B mismatches. Clin Transpl. 1989:185.

4. Claas FH, Witvliet MD, Duquesnoy RJ, Persijn GG, Doxiadis II. The acceptable mismatch program as a fast tool for highly sensitized patients awaiting a cadaveric kidney transplantation: short waiting time and excellent graft outcome. Transplantation. 2004;78:190.

5. Claas FH, Doxiadis II. Management of the highly sensitized patient. Curr Opin Immunol. 2009;21:1.

6. Claas FH, Rahmel A, Doxiadis II. Enhanced kidney allocation to highly sensitized patients by the acceptable mismatch program. Transplantation. 2009;88:447.

7. Jordan SC, Vo AA, Peng A, Toyoda M, Tyan D. Intravenous gammaglobulin (IVIG): a novel approach to improve transplant rates and outcomes in highly HLA-sensitized patients. Am J Transplant. 2006;6:459.

8. Vo AA, Lukovsky M, Toyoda M, Wang J, Reinsmoen NL, Lai CH et al. Rituximab and intravenous immune globulin for desensitization during renal transplantation. N Engl J Med. 2008;359:242.

9. Duquesnoy RJ, Marrari M. HLAMatchmaker-based definition of structural human leukocyte antigen epitopes detected by alloantibodies. Curr Opin Organ Transplant. 2009;14:403.
10. Morales-Buenrostro LE, Terasaki PI, Marino-Vázquez LA, Lee JH, El-Awar N, Alberú J. "Natural" human leukocyte antigen antibodies found in nonalloimmunized healthy males. Transplantation. 2008;86:1111.

11. Goodman RS, Taylor CJ, O'Rourke CM, Lynch A, Bradley JA, Key T. Utility of HLAMatchmaker and single-antigen HLA-antibody detection beads for identification of acceptable mismatches in highly sensitized patients awaiting kidney transplantation. Transplantation. 2006;81:1331.

12. Duquesnoy RJ, Witvliet M, Doxiadis II, de Fijter H, Claas FH. HLAMatchmakerbased strategy to identify acceptable HLA class I mismatches for highly sensitized kidney transplant candidates. Transpl Int. 2004;17:22.

13. Zachary AA, Sholander JT, Houp JA, Leffell MS. Using real data for a virtual crossmatch. Hum Immunology. 2009;70:574.

14. Ho EK, Vasilescu ER, Colovai AI, Stokes MB, Hallar M, Markowitz GS, et al. Sensitivity, specificity and clinical relevance of different cross-matching assays in deceased-donor renal transplantation. Transplant Immunology. 2008;20:61.

15. Watson N, Weston L, Abou-Daher F, Gavin R, Rosales B, Bryant J. Correlation of flow cytometric crossmatch and luminex for the detection of HLA antibodies. Hum Immunol 2009; 70, Supplement 1: S48.

16. Schmitz JL, Collins D, Crawford J, Petraroia R, Crawford T, Furmage N, Jimenez H. Prediction of flow cytometry and AHG-CDC crossmatch results by multiplex bead array MFI. Hum Immunol 2009; 70, Supplement 1: S38.

17. Bryan CF, Luger AM, Smith JL, Warady BA, Wakefield M, Schadde E, et al. Sharing kidneys across donor-service area boundaries with sensitized candidates can be influenced by HLA C. Clin Transplant. 2010;24:56. 